\title{
BMJ Children's surgery: a national survey Open of consultant clinical practice
}

\author{
David G Mason, ${ }^{1}$ Hannah Shotton, ${ }^{2}$ Kathleen A Wilkinson, ${ }^{3}$ Michael J Gough, ${ }^{4}$ \\ Robert Alleway, ${ }^{2}$ Heather Freeth, ${ }^{2}$ Marisa Mason ${ }^{2}$
}

To cite: Mason DG, Shotton H, Wilkinson KA, et al. Children's surgery: a national survey of consultant clinical practice. BMJ Open 2012;2: 0001639 .

doi:10.1136/bmjopen-2012001639

- Prepublication history and additional material for this paper are available online. To view these files please visit the journal online ((http://dx. doi.org/10.1136/bmjopen2012-001639).

Received 25 June 2012 Accepted 30 August 2012

This final article is available for use under the terms of the Creative Commons Attribution Non-Commercial 2.0 Licence; see http://bmjopen.bmj.com

\footnotetext{
${ }^{1}$ Nuffield Department of Anaesthesia, Oxford University Hospitals NHS Trust, Oxford, UK ${ }^{2}$ National Confidential Enquiry into Patient Outcome and Death (NCEPOD), London, UK ${ }^{3}$ Department of Anaesthesia, Norfolk and Norwich University Hospitals NHS Foundation Trust, Norfolk, UK ${ }^{4}$ Department of Surgery, Leeds Teaching Hospitals NHS Trust, West Yorkshire, Leeds, UK
}

\section{Correspondence to} Dr Hannah Shotton; hshotton@ncepod.org.uk

\section{ABSTRACT}

Objectives: To survey clinical practice and opinions of consultant surgeons and anaesthetists caring for children to inform the needs for training, commissioning and management of children's surgery in the UK.

Design: The National Confidential Enquiry into Patient Outcome and Death (NCEPOD) hosted an online survey to gather data on current clinical practice of UK consultant surgeons and anaesthetists caring for children.

Setting: The questionnaire was circulated to all hospitals and to Anaesthetic and Surgical Royal Colleges, and relevant specialist societies covering the UK and the Channel Islands and was mainly completed by consultants in District General Hospitals.

Participants: 555 surgeons and 1561 anaesthetists completed the questionnaire.

Results: $32.6 \%$ of surgeons and $43.5 \%$ of anaesthetists considered that there were deficiencies in their hospital's facilities that potentially compromised delivery of a safe children's surgical service. Almost $10 \%$ of all consultants considered that their postgraduate training was insufficient for current paediatric practice and $20 \%$ felt that recent Continued Professional Development failed to maintain paediatric expertise. $45.4 \%$ of surgeons and $39.2 \%$ of anaesthetists considered that the current specialty curriculum should have a larger paediatric component. Consultants in non-specialist paediatric centres were prepared to care for younger children admitted for surgery as emergencies than those admitted electively. Many of the surgeons and anaesthetists had $<4 \mathrm{~h} /$ week in paediatric practice. Only $55.3 \%$ of surgeons and $42.8 \%$ of anaesthetists participated in any form of regular multidisciplinary review of children undergoing surgery.

Conclusions: There are significant obstacles to consultant surgeons and anaesthetists providing a competent surgical service for children. Postgraduate curricula must meet the needs of trainees who will be expected to include children in their caseload as consultants. Trusts must ensure appropriate support for consultants to maintain paediatric skills and provide the necessary facilities for a high-quality local surgical service.

\section{INTRODUCTION}

Approximately half a million children and young people undergo anaesthesia and surgery

\section{ARTICLE SUMMARY}

Article focus

- Do surgeons and anaesthetists involved in caring for children feel that the service provided is adequate?

\section{Key messages}

- This study highlights current deficiencies in postgraduate surgical and anaesthetic training, in delivery of continuing professional development and in NHS provision of surgical facilities for children.

Strengths and limitations of this study

- The strengths of this study are that it was selfreported data by clinicians involved in the care of children. Anonymity allowed for great honesty and surgeons and anaesthetists from all hospitals in the UK including the Offshore Islands were invited to participate, there was no selection applied. The limitation was that anonymity prevented the response rate to be accurately determined.

each year in England and Wales. ${ }^{1}$ There has been a considerable change in the delivery of surgical services for children in the UK over the past 20 years. This has resulted from the growing realisation that there is a need for concentration of clinical expertise, and workload along with specialised facilities for some children requiring surgery. This has followed numerous publications advocating high-quality child-centred services. $^{2-10}$ The majority of children's surgery are still undertaken in District General Hospitals (DGH) but there have been a gradual reduction in the range and volume of procedures performed outside Specialist Tertiary Paediatric Centres (STPC). ${ }^{1}$ While the requirement for specialist centres to undertake more complex surgery is clearly appropriate, some of the reduction in local provision may reflect changes in postgraduate surgical and anaesthetic training, and greater subspecialisation by consultant surgeons and anaesthetists. As a consequence, there is growing concern that surgeons and anaesthetists in DGHs are 
Table 1 Category of hospital in which respondents were employed

\begin{tabular}{lccrr}
\hline Hospital category & Surgical & Percentage & Anaesthetic & Percentage \\
\hline District General Hospital (DGH) & 320 & 57.7 & 974 & 62.4 \\
Specialist Tertiary Paediatric Centre (STPC) & 89 & 16.0 & 167 & 10.7 \\
University Teaching Hospital (UTH) & 138 & 24.9 & 391 & 25.0 \\
Private Hospital (PH) & 3 & 0.5 & 5 & 0.3 \\
Single Specialist Hospital (SSH) & 6 & 1.1 & 1561 & 1.5 \\
Grand total & 555 & & \\
\hline
\end{tabular}

becoming deskilled in the care of children requiring routine elective and emergency surgery. ${ }^{11}$ An important consequence of this is likely to be a lack of confidence in management of the critically ill child. ${ }^{12}$ Thus, it has been suggested that we might reach a tipping point where the surgical and anaesthetic care of children in DGHs becomes unsustainable. National organisations have called for an urgent review of these services to ensure their viability. $^{13-16}$

In this survey we focused on the views of individual clinicians about their ability to provide surgical and anaesthetic care for children, rather than organisational issues. In 1989 and 1999, the NCEPOD undertook a limited survey of the number of children cared for by individual consultant surgeons and anaesthetists by age. $^{217}$ and there have been no similar surveys in the last 10 years. We considered that this would be valuable to inform future planning.

\section{METHODS}

An online questionnaire was devised to survey consultant surgeons and anaesthetists in the UK about their clinical paediatric practice. The questionnaire determined whether the consultant cared for children and young people $<16$ years of age, their clinical specialty, number of years as a consultant and the category of hospital in which they worked. Consultants were also asked about the lower age limit of children they were happy to care for and whether they participated in multidisciplinary care reviews, audit, morbidity and mortality meetings, and about the factors that potentially limited the safety of their practice. Finally, their views on their postgraduate training and continuing professional development (CPD) were also determined.

Invitations and reminders to participate in the survey were sent between June and December 2010 using online advertising and email communication via several routes (Association of Anaesthetists Great Britain and Ireland, Association of Surgeons Great Britain and Ireland, Royal College of Anaesthetists, Royal College of Surgeons ofEngland, Association of Paediatric Anaesthetists Great Britain and Ireland, and British Association of Paediatric Surgeons). In addition, a letter was sent to anaesthetic departments of all UK hospitals informing them of the survey. Data analysis and tabulation were performed using Microsoft Excel (2003).

\section{RESULTS}

In total 2116 questionnaires were completed by consultants who cared for children $<16$ years of age (555 surgeons and 1561 anaesthetists). The majority of consultants worked in a DGH (table 1) and the largest surgical group were general surgeons. The categories displayed comprise both surgeons who have dedicated paediatric practice and those who have an interest (figure 1). The median number of years in post was 11 (IQR 6-16) for surgeons and 10 (IQR 5-16) for anaesthetists. Therefore, those who had gained CCT relatively recently were highly represented in this survey.

\section{Elective and emergency care: age of children}

For elective care the majority of the responding DGH surgeons used a lower age limit of 5 years, whereas for anaesthetists most would care for 1-year-olds to 2-year-olds. Although there was considerable variation in these ages depending on the category of hospital in which the consultants worked a common finding was that many would be prepared to care for children of a younger age as an emergency compared with that for elective procedures. This was particularly the case for consultants working in a DGH (figures 2 and 3).

\section{Time devoted to paediatric practice}

Responders were asked to provide information on the number of $4 \mathrm{~h}$ units of professional activity (PA) per

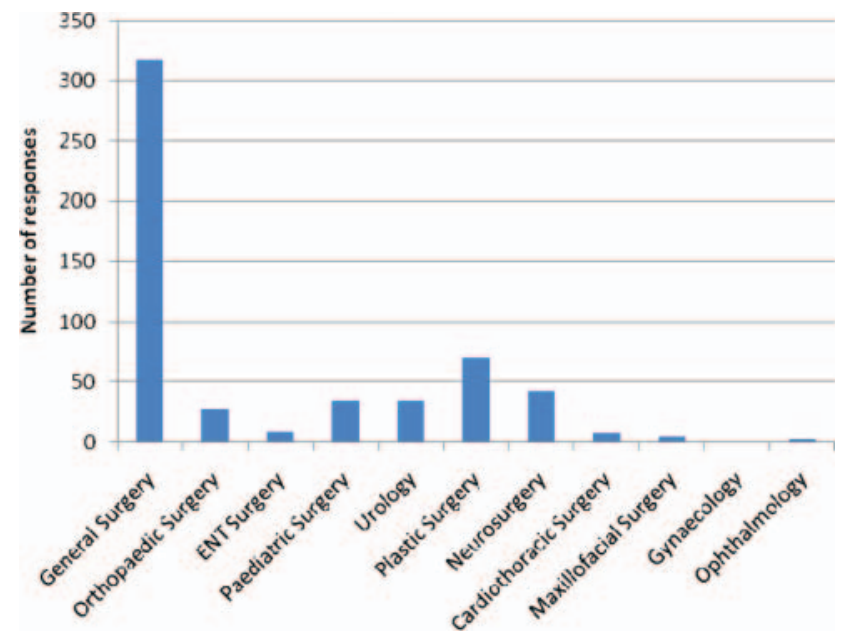

Figure 1 Specialty of consultant surgeons completing the questionnaire. 


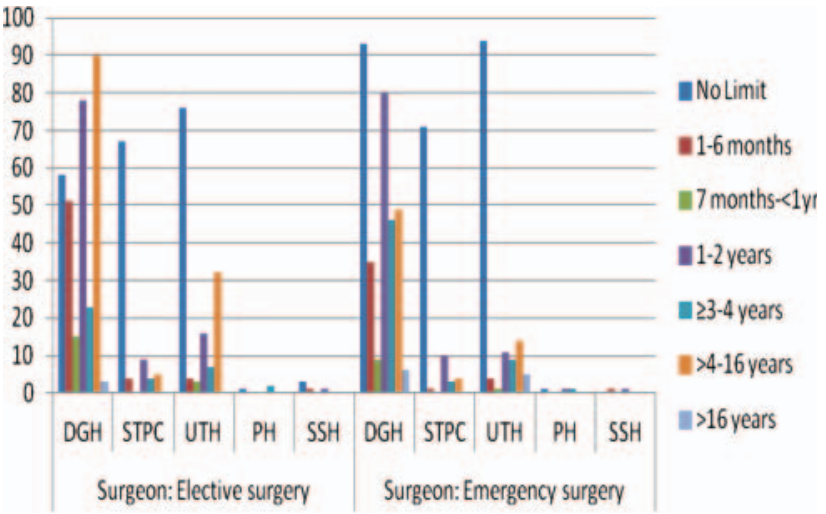

Figure 2 Minimum age that surgeons would operate on children by category of hospital for elective and emergency surgery.

week devoted to the care of children (figures 4 and 5). In total $213 / 555(38 \%)$ of surgeons and $659 / 1561(42 \%)$ of anaesthetists had $<1$ PA per week allocated for the care of children. In total $70 / 555(12.6 \%)$ of surgeons and $151 / 1561(9.6 \%)$ of anaesthetists did not have any dedicated PAs.

\section{Training, CPD and data collection}

Consultants were asked whether their postgraduate training had adequately prepared them for their current paediatric practice. Of respondents 52/555 (9.3\%) of surgeons and $139 / 1561(8.9 \%)$ of anaesthetists indicated that this was not the case. Most of these had been in post for $\leq 10$ years $(35 / 52 \quad(67.3 \%)$ of surgeons, $71 / 139(51 \%)$ of anaesthetists). The commonest reasons for this was said to be lack of time within their training programme $(64 / 191,33.5 \%)$ and insufficient emphasis $(26 / 191,13.6 \%)$ on paediatric care within the specialty curriculum. Further, 252/555 (45.4\%) surgeons and $612 / 1561(39.2 \%)$ anaesthetists felt that the current curriculum for their specialty should have a larger paediatric component. Table 2 indicates the proportion of

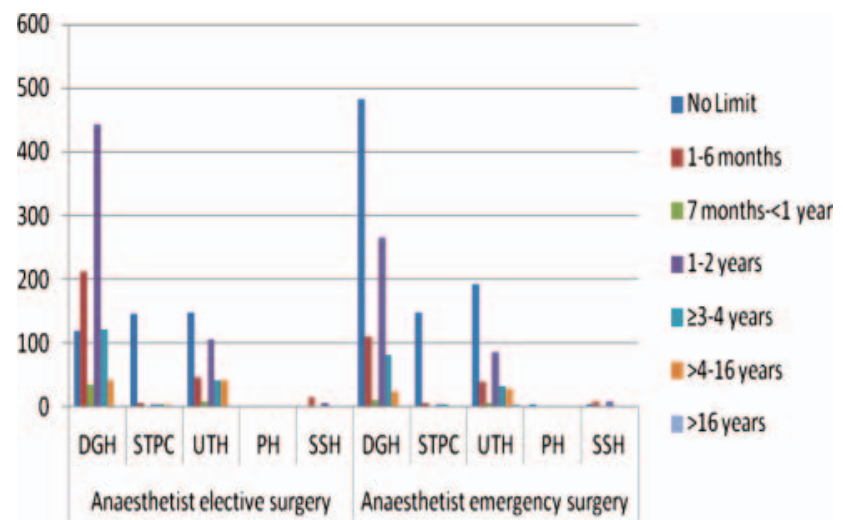

Figure 3 Minimum age that anaesthetists would anaesthetise children by category of hospital for elective and emergency surgery.

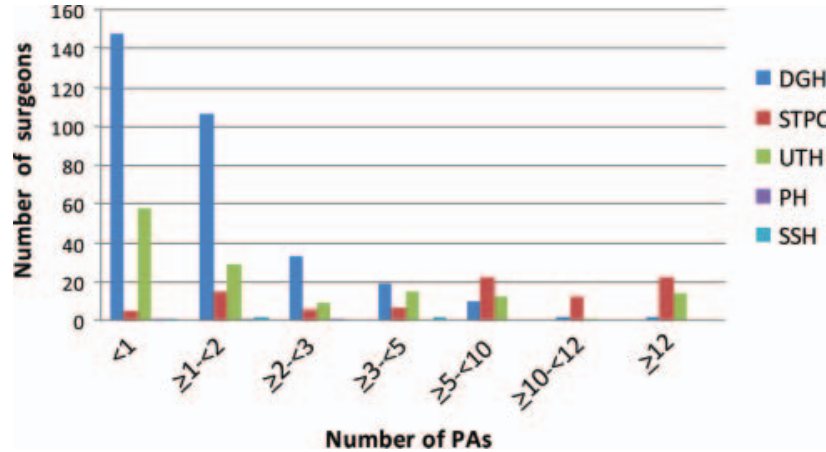

Figure 4 The number of $4 \mathrm{~h}$ units of professional activity (PA) devoted to the care of children by hospital category for surgeons.

training time that these respondents believed should be devoted to paediatric practice with anaesthetists suggested a greater increase in this than their surgical counterparts.

In relation to $\mathrm{CPD}$, consultants were asked about the type of activity they had undertaken in the last 3 years that was specifically relevant to their paediatric practice (table 3). Of these, 113/555 (20.3\%) of surgeons and $364 / 1561(23.3 \%)$ of anaesthetists $\mathrm{did}$ not believe that these types of CPD had been sufficient to maintain or update their expertise in their paediatric practice. Further, only about a third of responding surgeons had undertaken a course to update their skills. The reasons cited for this are shown in table 4 with the most being a lack of funding or study leave provided by their hospitals.

Most respondents, $1719 / 2116 \quad(81.2 \%)$ collected information on their paediatric practice for audit and/or appraisal purposes although this was more prevalent among anaesthetists $(1350 / 1561,86.5 \%$ vs $396 / 555$, $71.3 \%)$. The use of a personal logbook was the most widely used method for this (table 5).

\section{Critical factors limiting safe paediatric practice}

Consultants were asked to rank factors from a provided list, in order of importance, to indicate whether they limited their ability to undertake safe paediatric practice.

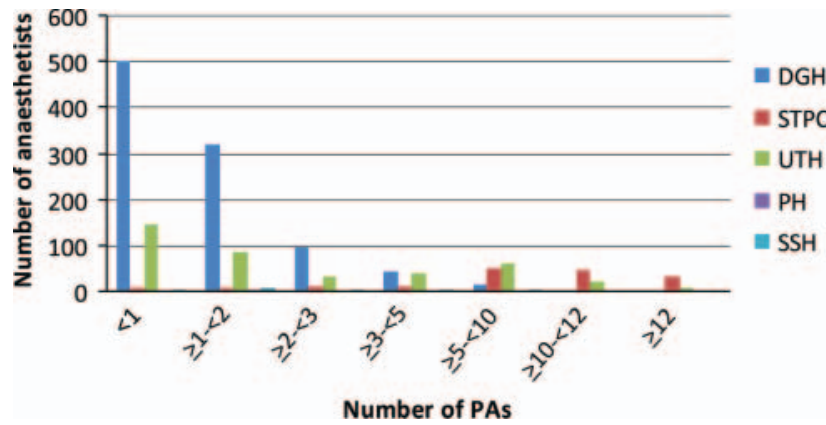

Figure 5 The number of $4 \mathrm{~h}$ units of professional activity (PA) devoted to the care of children by hospital category for anaesthetists. 
Table 2 Proportion of the training curriculum that it was considered should be devoted to paediatric practice by those consultants that believed it should be increased

\begin{tabular}{|c|c|c|c|c|c|}
\hline Proportion of curriculum (\%) & Surgical & Percentage & Anaesthetist & Percentage & Total \\
\hline $0-10$ & 131 & 56.2 & 169 & 31.8 & 300 \\
\hline $11-19$ & 32 & 13.7 & 104 & 19.5 & 136 \\
\hline 20-25 & 52 & 22.3 & 233 & 43.8 & 285 \\
\hline$>25$ & 18 & 7.7 & 26 & 4.9 & 44 \\
\hline Subtotal & 233 & & 532 & & 765 \\
\hline Not answered & 19 & & 80 & & 99 \\
\hline Total & 252 & & 612 & & 864 \\
\hline
\end{tabular}

Factors ranked among the three most important by each respondent were assigned a score of 3 (most important), 2 (second most important) or 1 (ranked third). The cumulated scores for each factor are depicted in figure 6 . The main factors that surgeons considered as compromising safety were: the skills of their anaesthetist, the facilities in which procedures were undertaken, and the comorbidities and age of the child. Lack of hospital facilities also were considered critical by anaesthetists who also focused on comorbidities, age and paediatric workload.

\section{Deficiencies in hospital facilities for safe paediatric care} In all 181/555 (32.6\%) surgeons and 679/1561 (43.5\%) anaesthetists believed that there were deficiencies in their hospital facilities that precluded safe practice, regardless of the type of hospital. Where hospitals facilities were considered unsatisfactory consultants were asked to rank these using a predefined list. A lack of adequately trained theatre and anaesthetic assistance were identified as the most critical factor by both surgeons and anaesthetists followed by inadequate organisational arrangements for the care of children and insufficient hospital management support (figure 7).

\section{Multidisciplinary review}

Tables 6 and 7 indicate the proportion of consultants participating in any form of regular multidisciplinary team review of children subdivided by the category of hospital in which they worked. This analysis reveals that many consultants do not engage in this type of activity, particularly if working in a DGH. Of respondents who did undertake this type of activity the majority attended audit and morbidity meetings (table 8 ).

\section{DISCUSSION}

We present a large-scale survey of the clinical practice and opinions of consultant surgeons and anaesthetists who care for children in the UK.

There are a number of limitations of this study. While every effort was made to identify all consultant surgeons and anaesthetists in the UK who are involved in the treatment of children $<16$ years of age this information is not readily available. In 1999, when NCEPOD last collated data on this subject $72 \%$ of anaesthetists and $67 \%$ of surgeons said they had a paediatric practice (children up to their 16th birthday), but this may have changed in the intervening years. ${ }^{17}$ Further, although consultant numbers have been collated by the Royal College of Surgeons of England and the Royal College of Anaesthetists those with a paediatric practice have not been identified separately. Thus, a denominator for this survey cannot be determined. As stated earlier, many methods were employed to inform consultants of the survey and encourage them to complete it. However, it is possible that respondents with a

Table 3 Type of continuing professional development activity for the care of children undertaken by consultants in the last 3 years

\begin{tabular}{|c|c|c|c|c|}
\hline \multirow[b]{2}{*}{ Type of continued professional development } & \multicolumn{2}{|c|}{ Surgeons $(n=555)$} & \multicolumn{2}{|c|}{ Anaesthetists $(n=1561)$} \\
\hline & $\bar{n}$ & Percentage & n & Percentage \\
\hline (a) Presenting work & 152 & 27.4 & 305 & 19.5 \\
\hline (b) Course-skills update & 174 & 31.4 & 911 & 58.4 \\
\hline (c) Course-specific technique & 77 & 13.9 & 284 & 18.2 \\
\hline (d) Private study & 283 & 51.0 & 781 & 50.0 \\
\hline (e) Overseas experience & 68 & 12.3 & 99 & 6.3 \\
\hline (f) Symposium/conference & 215 & 38.7 & 704 & 45.1 \\
\hline (g) Observation of clinical practice & 137 & 24.7 & 488 & 31.3 \\
\hline (h) Professional examination & 38 & 6.8 & 73 & 4.7 \\
\hline (i) Professional society meeting & 175 & 31.5 & 483 & 30.9 \\
\hline (j) Other & 98 & 17.7 & 107 & 6.9 \\
\hline
\end{tabular}


Table 4 Reasons given by consultants for insufficient continuing professional development (CPD) to maintain expertise in paediatric practice

\begin{tabular}{lllrr}
\hline Reason given & Surgeons $(\mathbf{n = 7 9 )}$ & Percentage & Anaesthetist $(\mathbf{n = 2 2 1 )}$ & Percentage \\
\hline (a) Lack of funding & 28 & 35.4 & 89 & 40.3 \\
(b) Lack of study leave & 30 & 38.0 & 107 & 48.4 \\
(c) Do not consider this type of CPD relevant & 19 & 24.1 & 20 & 9.0 \\
(d) Poor quality of type of CPD attended & 8 & 10.1 & 35 & 15.8 \\
(e) Other & 16 & 20.2 & 27 & 12.2 \\
\hline
\end{tabular}

Answers are multiple: surgeons 34 not answered; anaesthetists: 143 not answered.

particular interest in the underlying issues relating to children's surgery and anaesthesia were more likely to respond. Despite this, the survey provides an interesting insight into the practice and opinions of UK consultant surgeons and anaesthetists.

In retrospect, more detailed information could have been sought on some aspects of clinical practice: for example, workload and case mix, team working and on call arrangements as well as deficiencies in postgraduate training. However, the number of questions was kept relatively short to encourage compliance.

A striking finding of this survey was the similarity in the answers provided by surgeons and anaesthetists. The type of hospital in which the respondents worked and their years of employment were similar. About half of the surgeons completing the survey were general surgeons. Although the precise number of general surgeons with an interest in paediatric surgery is unknown the survey should reflect the views of a large proportion of this group. Certainly the number of surgeons who replied must represent a large proportion of the 138 (elective surgery) and 147 (elective and emergency) non-specialist hospitals in England, Wales and Northern identified in a survey published in 2008. ${ }^{11}$ Nevertheless, the low number of responses from other surgical specialties must be recognised before generalising the findings of this survey.

Table 5 Methods used to collect information on paediatric practice

\begin{tabular}{|c|c|c|c|c|}
\hline \multirow{2}{*}{$\begin{array}{l}\text { Methods of } \\
\text { collection }\end{array}$} & \multicolumn{2}{|c|}{ Surgeons } & \multicolumn{2}{|c|}{ Anaesthetist } \\
\hline & $\mathbf{n}$ & Percentage & $\mathbf{n}$ & Percentage \\
\hline $\begin{array}{l}\text { Personal log } \\
\text { book }\end{array}$ & 294 & 74.4 & 925 & 68.8 \\
\hline $\begin{array}{l}\text { Hospital } \\
\text { database }\end{array}$ & 194 & 49.1 & 617 & 45.9 \\
\hline $\begin{array}{l}\text { National } \\
\text { database }\end{array}$ & 66 & 16.7 & 7 & 0.5 \\
\hline Other audit & 6 & 1.5 & 2 & 0.1 \\
\hline Other & 6 & 1.5 & 3 & 0.2 \\
\hline Subtotal & 395 & & 1344 & \\
\hline Not answered & 1 & & 6 & \\
\hline Total & 396 & & 1350 & \\
\hline
\end{tabular}

There has been considerable debate over the last two decades about who should operate on and who should anaesthetise children in the UK. ${ }^{217-22}$ Further, numerous strategies have been suggested to ensure that consultants obtain and maintain their competencies; these include postgraduate training, years of experience, workload load by age of child and CPD. ${ }^{12} 2023-25$ In this survey we have attempted to explore some of these factors. Thus, we found that many consultants from DGHs and University Teaching Hospitals (UTH) would care for younger children, or without limit to age for emergency surgery while restricting elective surgery to older children. This is not surprising and has been reported previously by NCEPOD and the Children's Surgical Forum (CSF) of the Royal College of Surgeons, England. ${ }^{2} 1726$ This reflects the necessity of providing an emergency service, particularly in DGHs that may be geographically isolated where the ability to provide rapid transfer to a larger centre may result in unacceptable delay. Further, these children may present to at a DGH where there is an insufficient workload to justify a separate consultant on call provision for children. Consequently, consultant surgeons and

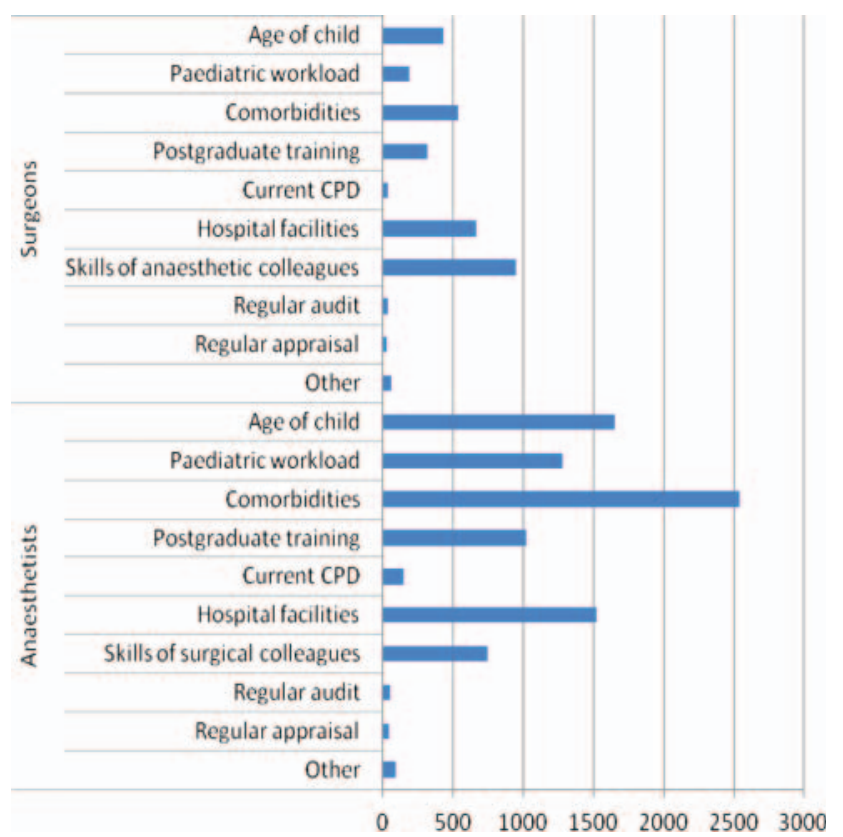

Figure 6 Highest ranked factors that limit the ability of consultants to undertake a safe paediatric practice. 


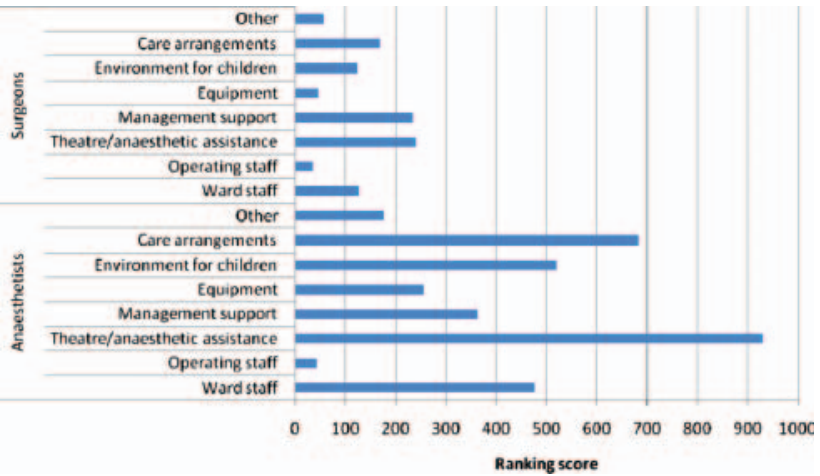

Figure 7 Highest-ranked deficiencies in hospital facilities to provide a safe paediatric practice.

anaesthetists who have no alternative but to care for the child locally, particularly out of hours, will have varying paediatric experience. There is no easy solution to this situation other than good cooperation and funded arrangements between STPCs, DGHs and UTH. ${ }^{12} 132427$ Formal-managed networks of care for children's surgery have been advocated as a means for achieving this. ${ }^{9} 2428$

While case numbers may facilitate the maintenance of skills and competence, time allocated to paediatric practice is also important. Given the new consultant contract the number of PAs for paediatric care by surgeons and anaesthetists should be easier to measure. Data from this survey reveal that many consultants, particularly from DGHs, have $<1 \mathrm{PA}$ devoted to paediatric practice each week and thus maintenance of competencies will be particularly difficult for them. In these circumstances detailed review of their paediatric practice will be essential for appraisal and revalidation purposes. It is encouraging that the majority of consultants who completed this questionnaire collected this information in one form or another.

Postgraduate training is the bedrock of future consultant practice. Thus, a curriculum that includes an adequate component of paediatric training is essential. It is therefore of concern that $9.3 \%$ of surgeons and $8.9 \%$ of anaesthetists completing this survey believed that their postgraduate training had not prepared them for their current level of paediatric practice. This was particularly the case for those who trained in the last 10 years where it was felt that inadequate time and emphasis were devoted to paediatric training. Furthermore, $45.4 \%$ of surgeons and $39.2 \%$ of anaesthetists felt that the curriculum for their specialty should have a greater paediatric component. Revision of the general surgery curriculum in 2010 now includes three modules in paediatric surgery, but these are special interest modules and paediatric surgery was even less formal in earlier versions. From a trainees' perspective there is the risk that they see themselves as surgeons in their chosen specialty, and with the exception of paediatric surgery, it is not until they are appointed as a consultant that they may realise that a period of training in children's surgery would have been of benefit. In this respect the UK general surgical curriculum has had no mandatory paediatric component for more than 10 years and both the availability and take-up of optional modules in children's surgery has been poor. In contrast, the anaesthetic curriculum includes compulsory paediatric modules at intermediate and higher levels ${ }^{29} 30$ However, most anaesthetists who felt there were deficiencies in training thought that $20-25 \%$ of training time should be dedicated to paediatrics.

Continuing professional development is an essential part of consultant activity and should be proportionate to clinical practice. In the current economic climate within the NHS there is considerable pressure on supporting this for consultants both in terms of time and funding. In this survey, one in five consultant surgeons and anaesthetists reported that these factors prevented adequate CPD to maintain their expertise in paediatric practice.

In summary therefore inadequate postgraduate training, limited clinical time within job plans (PA allocation), and difficulty in accessing CPD are important factors that consultant surgeons and anaesthetists believe adversely affects the quality of service that they are able to deliver for children's surgery.

There are other factors that may limit an individual consultant's practice in relation to children's surgery. Surgeons considered that the skills of anaesthetic colleagues were paramount while anaesthetists reported that a child's comorbidities were the most important factor. It is logical that most surgeons considered that anaesthetic skills were the most important factor limiting their ability to undertake safe surgical care. Without this surgical practice is severely restricted.

A safe surgical service also requires adequate hospital facilities and thus it is concerning that $32.6 \%$ of surgeons and $43.5 \%$ of anaesthetists considered that there were deficiencies in their hospital's provision of a safe paediatric service. Although this could be a counsel of

Table 6 Participation by surgeons in regular multidisciplinary review of children who undergo surgery

\begin{tabular}{lrcrrr}
\hline Hospital category & Yes & Percentage & No & Percentage & Not answered \\
\hline District General Hospital (DGH) & 134 & 41.8 & 186 & 58.1 & 320 \\
Specialist Tertiary Paediatric Centre (STPC) & 78 & 87.6 & 11 & 12.4 & 89 \\
University Teaching Hospital (UTH) & 94 & 68.1 & 43 & 31.2 & 1 \\
Private Hospital (PH) & & 0 & 3 & 100.0 & 138 \\
Single Specialist Hospital (SSH) & 1 & 20.0 & 4 & 80.0 & 3 \\
Grand total & 307 & 55.3 & 247 & 44.5 & 1 \\
\hline
\end{tabular}


Table 7 Participation by anaesthetists in regular multidisciplinary review of children who undergo surgery

\begin{tabular}{lrlrrr}
\hline Hospital category & Yes & Percentage & No & Percentage & Grand total \\
\hline District General Hospital (DGH) & 334 & 34.3 & 640 & 65.7 & 974 \\
Specialist Tertiary Paediatric Centre (STPC) & 144 & 86.2 & 23 & 13.8 & 167 \\
University Teaching Hospital (UTH) & 171 & 43.6 & 221 & 56.4 & 392 \\
Private Hospital (PH) & 3 & 60.0 & 2 & 40.0 & 5 \\
Single Specialist Hospital (SSH) & 16 & 69.6 & 7 & 30.4 & 23 \\
Grand total & 668 & 42.8 & 893 & 57.2 & 1561 \\
\hline
\end{tabular}

Table 8 Form of multidisciplinary review undertaken by consultants

\begin{tabular}{lcccc}
\hline Form of review & Anaesthetist $(\mathbf{n = 6 5 6 )}$ & Percentage & Surgeon $(\mathbf{n = 3 0 3 )}$ & Percentage \\
\hline Preoperative MDT & 82 & 12.5 & 100 & 33.0 \\
Audit meetings & 490 & 74.7 & 197 & 65.0 \\
M\&M meetings & 392 & 59.8 & 216 & 71.3 \\
Informal discussions with Colleagues & 373 & 56.9 & 174 & 57.4 \\
Other & 18 & 2.7 & 15 & 5.0 \\
\hline
\end{tabular}

Answers may be multiple.

MDT, multidisciplinary team.

perfection among respondents recurring themes were the lack of trained paediatric staff in the operating theatre, insufficient paediatric nurses on children's wards and inadequacies of the organisational arrangements for the care of children in their hospital. These are all are potentially remediable if prioritised by Colleges, professional organisations and Trusts.

Clinical governance and audit is now embedded in every aspect of healthcare. Hospitals are required to adhere to guidelines on clinical governance and medical practitioners are required to undertake regular review of clinical practice. ${ }^{31} 32$ Furthermore multidisciplinary team review is an integral part of modern healthcare and has a valuable role in determining the best care. Thus, it is of concern that only $55.3 \%$ surgeons and $42.8 \%$ of anaesthetists participated in any form of multidisciplinary review of children undergoing surgery. In the latest NCEPOD study reviewing surgery in children we found that only $50 \%$ hospitals undertook audit and/or morbidity and mortality meetings that included children. While this deficiency was particularly an issue in DGHs it might be argued that a forum for sharing clinical experience is particularly important for DGH consultants with a relatively small the workload.

In conclusion, while one might argue whether the findings of this survey are representative of all consultant surgeons and anaesthetists who care for children in the $\mathrm{UK}$, it is disturbing that this group of clinicians reported so many obstacles in place to providing a safe paediatric service. Those responsible for postgraduate training of should review the current curricula to ensure that they more adequately support the clinical responsibilities of prospective consultant surgeons and anaesthetists in DGHs who, by necessity, will have a paediatric component to their practice. Furthermore, to ensure that these consultants do not feel exposed and under undue pressure to practise at the limit of their competency, greater cooperation will be required between all categories of hospital that care for children requiring surgery. Finally, all hospitals that provide children's surgery have a responsibility to ensure that consultant surgeons and anaesthetists who have children in their patient caseload are supported in their practice, that they have adequate opportunity to enhance and maintain their skills, and have the necessary facilities in place for children's care, within a clear clinical governance structure.

Acknowledgements The authors would like to thank the Association of Anaesthetists of Great Britain and Ireland, Association of Surgeons of Great Britain and Ireland, Royal College of Anaesthetists, Royal College of Surgeons of England, Association of Paediatric Anaesthetists of Great Britain and Ireland and the British Association of Paediatric Surgeons for their assistance in advertising the survey.

Contributors DGM developed the idea for the study; HS undertook the analysis of the data; KAW reviewed the data and advised on the study; MJG reviewed the data and advised on the study; RA set up the information system to collect the data; HF edited and reviewed the data and MM-Chief Executive of NCEPOD-edited the final document and acts as guarantor.

Funding This work was funded as part of the Clinical Outcome Programme, covering the department of Health England, the Welsh Assembly Government, the Department of Health, Social Services and Public Safety Northern Ireland and the Public Hospitals of Jersey, Guernsey and the Isle of Man.

Competing interests None.

Data sharing statement There are no additional data available.

\section{REFERENCES}

1. Cochrane H, Tanner S. Trends in children's surgery 1994-2005: evidence from Hospital Episodes Statistics Data. London: Department of Health, 2007.

2. Campling EA, Devlin HB, Lunn JN. The 1989 report of the National Confidential Enquiry into perioperative deaths. London: NCEPOD, 1990.

3. Department of Health. Getting the Right Start: National Service Framework for Children, Young People and Maternity Services Part 1: Standard for Hospital Services. 2003. Crown Copyright. 
4. Healthcare Commission. Improving services for children in hospital. 2007. Commission for Healthcare Audit and Inspection.

5. Department of Health. Every child matters in the health service. 2006. Crown Copyright.

6. Department for Children, Schools and Families. The children's plan; building brighter futures. 2007. Crown Copyright.

7. Shribman S. Children's health, our future: a review of progress against the National Service Framework for Children, Young People and Maternity Services 2004. London: Department of Health, 2007.

8. Department of Health. Healthy lives, brighter futures-the strategy for children and young people's health. 2009. Crown Copyright.

9. Kennedy I. Getting it right for children and young people: overcoming cultural barriers in the NHS so as to meet their needs. London: Department of Health, 2010 Crown Copyright.

10. Royal College of Paediatrics and Child Health. Facing the future: standards for paediatric services. London: RCPCH, 2011.

11. Pye JK. Survey of general paediatric surgery provision in England, Wales and Northern Ireland. Ann R Coll Surg Engl 2008;90:193-7. doi:10.1308/003588408X285766

12. Department of Health. The acutely or critically sick or injured child in the District General Hospital-a team response. 2006. http://webarchive.nationalarchives.gov.uk/+/www.dh.gov.uk/en/ Consultations/Closedconsultations/DH_4124412 (last accessed 7 Oct 2012).

13. Association of Paediatric Anaesthetists, Association of Surgeons for Great Britain and Ireland, British Association of Paediatric Surgeons, Royal College of Paediatrics and Child Health, Senate of Surgery for Great Britain and Ireland. Joint Statement on General Paediatric Surgery Provision in District General Hospitals in Great Britain and Ireland. London: BAPS, 2006. http://www.trainee.baps.org.uk/page4/ page37/assets/GPS\%20in\%20DGH.pdf (last accessed 7 Oct 2012).

14. National Steering Group for Specialist Children's Services. General Surgery of Childhood Report, Scotland, 2008. http://www. specialchildrensservices.scot.nhs.uk/Documents/org00005.pdf (last accessed 7 Oct 2012).

15. Craigie RJ, Duncan JL, Youngson GG. Children's surgery performed by adult general surgeons in Scotland: the present and future. Surgeon 2005;3:391-4

16. Mason DG, Wilkinson K, Gough MJ, et al. Are we there yet? A review of the organisational and clinical aspects of children's surgery. London: NCEPOD, 2011.

17. Extremes of Age. The 1999 Report of the National Confidential Enquiry into Perioperative Deaths. London: NCEPOD, 1999.
18. Atwell JD, Spargo PM. The provision of safe surgery for children. Archiv Dis Child 1992;67:345-9.

19. Arul GS, Spicer RD. Where should paediatric surgery be performed? Archiv Dis Child 1998;79:65-72.

20. Lunn JN. Implications of the National Confidential Enquiry into perioperative deaths for paediatric anaesthesia. Paediatr Anesth 1992;2:69-72.

21. McNicol R. Paediatric anaesthesia-who should do it? The view from the specialist hospital. Anaesthesia 1997;52:513-15.

22. Rollin AM. Paediatric anaesthesia-who should do it? The view from the specialist hospital. Anaesthesia 1997;52:515-16.

23. The Royal College of Surgeons of England. Surgery for children: delivering a first class service-report of the children's surgical forum. London: Royal College of Surgeons of England, 2007. http:// www.rcseng.ac.uk/publications/docs/CSF.html (last accessed 7 Oct 2012).

24. Children's Surgical Forum. Ensuring the provision of general paediatric surgery in the district general hospital: Guidance to commissioners and service planners. London: The Royal College of Surgeons of England, 2010.

25. The Paediatric Intensive Care Society. Standards for the care of critically ill children. 4th edn. ver 2. London: The Paediatric Intensive Care Society, 2010.

26. Children's Surgical Forum. General paediatric surgery: survey of service provision in District General Hospitals in England. London: The Royal College of Surgeons of England, 2010.

27. The Royal College of Anaesthetists. Guidance on the provision of paediatric anaesthesia services. London: Royal College of Anaesthetists, 2010.

28. Royal College of Paediatrics and Child Health. A guide to understanding pathways and implementing networks. London: Royal College of Paediatrics and Child Health, 2006

29. The Intercollegiate Surgical Curriculum Programme. The Intercollegiate Surgical Curriculum-General Surgery Syllabus August 2010. Intercollegiate Surgical Curriculum Programme.

30. The Royal College of Anaesthetists. Curriculum for a CCT in Anaesthetics. Edition 2, Version 1.4. August 2010 (updated June 2012) Royal College of Anaesthetists.

31. The Royal College of Surgeons of England. Children's surgery-a first class service: report of the paediatric forum of the Royal College of Surgeons of England. London: RCSENG, 2000, (reviewed: 2005).

32. General Medical Council. Good medical practice: guidance for doctors. 2006 (updated: 2009). General Medical Council. 